\title{
Genetic Diversity of Carpetgrass Germplasm Based on Simple Sequence Repeat Markers
}

\author{
Xiaoli Wang and Zhiyong Wang ${ }^{1}$ \\ Key Laboratory of Protection and Developmental Utilization of Tropical \\ Crop Germplasm Resources, Ministry of Education/College of Agriculture, \\ Hainan University, Haikou 570228, China
}

Li Liao and Xinyi Zhang
College of Agriculture, Hainan University, Haikou 570228, China

Changjun Bai

Tropical Pasture Research Center, Chinese Academy of Tropical Agricultural Sciences, Hainan Danzhou 571737, China

Additional index words. Axonopus compressus (Sw.) Beauv., germplasm resources, genetic relationship, molecular markers, UPGMA cluster analysis

\begin{abstract}
Carpetgrass [Axonopus compressus (Sw.) Beauv.] is an important warm-season perennial turfgrass that is widely used in tropical and subtropical areas. The genetic diversity of 63 carpetgrass accessions in China was studied using simple sequence repeat (SSR) markers. Fourteen SSR primer combinations generated a total of 49 distinct bands, $48(97.96 \%)$ of which were polymorphic. The number of observed alleles ranged from 2 to 6, with an average of 3.5. Coefficients of genetic similarity among the accessions ranged from 0.24 to 0.98 . Unweighted pair-group method with arithmetic means (UPGMA) clustered the 63 accessions into three groups, and not all samples from the same region belonged to the same group. SSR markers will promote marker-assisted breeding and the assessment of genetic diversity in wild germplasm resources of carpetgrass.
\end{abstract}

Carpetgrass [Axonopus compressus (Sw.) Beauv.] is a perennial warm-season turfgrass with many excellent characteristics, such as easy establishment and low management. Because of these traits, carpetgrass is often used to conserve soils and highway slopes and is planted as turf in common areas, sports fields, and shady areas in south China and around the world (Xi et al., 2004a). All individuals of carpetgrass are polyploid, with chromosome numbers $2 \mathrm{n}=4 \mathrm{x}=40,2 \mathrm{n}=5 \mathrm{x}$ $=50$, and $2 \mathrm{n}=6 \mathrm{x}=60$ (Delay et al., 1950), and the species is commonly cross-pollinated because of a self-incompatibility mechanism (Hanna and Burton, 1978). Carpetgrass is widely distributed in tropical and subtropical regions $\left(27^{\circ} \mathrm{N}-27^{\circ} \mathrm{S}\right)$ and adapted to a wide range of soil $\mathrm{pH}(\mathrm{pH} 4.1-7.1)$ and soil types (Heath et al., 1985; Liu, 2010). Natural hybrids have provided a very genetically rich germplasm of wild carpetgrass. Previous study revealed that carpetgrass accessions of south China had unique morphological and agronomic traits (Liao et al., 2011). However, the genetic diversity of wild carpetgrass germplasm

Received for publication 23 Dec. 2014. Accepted for publication 3 Apr. 2015.

This work was supported by the National Natural Science Foundation of China (31060266 and 31260489), and the Natural Science Foundation of Hainan (310031 and 314067).

${ }^{1}$ To whom reprint requests should be addressed; e-mailwangzhiyong7989@163.com. resources has been rarely explored, especially at the molecular level (Xi et al., 2004a). Thus, the purpose of this study was to assess this variation using molecular markers to advance the genetic breeding of carpetgrass.

Most studies of carpetgrass have focused on its genetic characteristics and resistance (Samarakoon et al., 1990; Smith and Whiteman, 1983; Uddin et al., 2009; Xi et al., 2006), but there is little information regarding its diversity on which to form a complete set of evaluation criteria. The existing studies are limited in the breadth of accessions examined (Xi et al., 2004a). The development of molecular biology has provided popular techniques to assess plant genetic diversity and analyze genetic variation using molecular markers. For lawn grass, analyses by both domestic and foreign scholars have identified a variety of molecular markers that can be applied to these tasks (Wang et al., 2009; Weng et al., 2007; Wu et al., 2006).

To explore genetic characteristics and diversity in plants, many types of molecular markers are available, including restriction fragment length polymorphism (RFLP), random amplified polymorphic DNA (RAPD), amplified fragment length polymorphism (AFLP), sequence-related amplified polymorphism (SRAP), and SSR (SSRs; also known as microsatellites) (Schlotterer, 2004; Weising et al., 2005). RAPD, AFLP, and SRAP are dominant markers that cannot detect whether an allele is heterozygous or homologous. Although RFLPs are codominant, the procedure is complex and requires high-quality DNA, so it is not conducive to automation for a large number of samples (Song et al., 2014). Therefore, SSRs have become the genetic markers of choice for many plant species because of their advantages over RFLPs, RAPDs, AFLPs (Pejic et al., 1998), and other DNA markers, such as intersimple sequence repeats (Wang et al., 2013). The advantages include uniform genome coverage, high polymorphism rates and informativeness, codominance, and the availability of specific polymerized chain reaction (PCR)-based assays. SSRs have been useful for other warm-season turfgrasses (Harris-Shultz et al., 2013; Madesis et al., 2014).

Axonopus has not been previously studied using microsatellite markers, therefore, we examined the genetic diversity of carpetgrass germplasms using SSRs. The results will provide important methods and technologies for future research. The objectives of this study were 1) to use an SSR marker system to study the genetic relationships among 63 carpetgrass accessions from China and 2) to describe the genetic variation in the accessions.

\section{Materials and Methods}

Plant material. Sixty-three carpetgrass accessions were collected from Hainan, Guangdong, Guangxi, Yunnan, Guizhou, and Fujian provinces of China (Table 1). The materials were grown under field conditions at Hainan University, Danzhou, Hainan Province, China $\left(19^{\circ} 31^{\prime} \mathrm{N}, 109^{\circ} 34^{\prime} \mathrm{E}\right.$, altitude $\left.131 \mathrm{~m}\right)$. The area has a tropical monsoon climate with an average annual rainfall of 1,815 $\mathrm{mm}$. The annual average sunlight exceeds $2,000 \mathrm{~h}$ with a solar radiation intensity of 34,244.6 Lux (14,012.2-53,587.4 Lux). The field temperature ranged from $9.0^{\circ} \mathrm{C}$ to $38.6{ }^{\circ} \mathrm{C}$ (average, $24.0^{\circ} \mathrm{C}$ ). All accessions were identified as carpetgrass based on the morphological characteristics described by Liu (2010).

Vegetatively propagated carpetgrass accessions (cultivars) were obtained from the suppliers listed in Table 1. All wild accessions were collected by gathering healthy stolons from the field. For each accession, $\approx 40$ healthy stem segments with two internodes each were planted in a regular array in a plot of $0.5 \times 0.5 \mathrm{~m}^{2}$. Plots of different accessions were separated by $50 \mathrm{~cm}$, and each plot was trimmed to prevent plot-to-plot contamination. The plots were frequently mowed to a height of $50 \mathrm{~mm}$ to ensure healthy turf and a supply of newly expanded leaf blades.

Although carpetgrass is widely distributed in south China, studies on the asexual reproduction characteristics of widespread indigenous accessions are lacking. The purpose of this study was to assess the genetic variation and the asexual reproduction characteristics among 63 carpetgrass accessions from China, the following measurements were preliminarily assessed: vertical growth (was calculated as the height of the grass layer divided by $28 \mathrm{~d}$ ), secondary stolon branches per unit perimeter [was calculated as the number of secondary branches in the 
plot divided by the plot perimeter $(2.0 \mathrm{~m})$, the same as below], horizontal growth rate of a single branch (was calculated as the total length of stolons in the plot divided by $28 \mathrm{~d}$ ), coefficient of expansion, and numbers of both primary.

DNA extraction. Genomic DNA of each carpetgrass accession was extracted from

Table 1. Sixty-three carpetgrass accessions used in the study.

\begin{tabular}{|c|c|c|c|c|c|}
\hline No. & Accession No. & Locations & No. & Accession No. & Locations \\
\hline 1 & A2 (Huanan) & $\begin{array}{l}\text { Chinese Academy of Tropical } \\
\text { Agricultural Sciences }\end{array}$ & 33 & A83 & Xiamen, Fujian \\
\hline 2 & A3 & Dingan, Hainan & 34 & A84 & Zhangpu, Fujian \\
\hline 3 & A4 & Dingan, Hainan & 35 & A86 & Changtai, Fujian \\
\hline 4 & A5 & Danzhou, Hainan & 36 & A 87 & Daxin, Guangxi \\
\hline 5 & A7 & Baisha, Hainan & 37 & A 88 & Fusui, Guangxi \\
\hline 6 & A15 & Qionghai, Hainan & 38 & A94 & Chongzuo, Guangxi \\
\hline 7 & A16 & Sanya, Hainan & 39 & A95 & Gelinnada \\
\hline 8 & A19 & Wenchang, Hainan & 40 & A97 & Tengchong, Yunnan \\
\hline 9 & A23 & Wanning, Hainan & 41 & A98 & Huaiji, Guangdong \\
\hline 10 & A25 & Guigang, Guangxi & 42 & A99 & Huaiji, Guangdong \\
\hline 11 & A28 & Chengmai, Hainan & 43 & $\mathrm{~A} 100$ & Fogang, Guangdong \\
\hline 12 & A30 & Qiongzhong,Hainan & 44 & A101 & Guiping, Guangxi \\
\hline 13 & A34 & Ledong, Hainan & 45 & $\mathrm{~A} 102$ & Tunchang, Hainan \\
\hline 14 & A37 & Danzhou, Hainan & 46 & A103 & Wuzhishan, Hainan \\
\hline 15 & A38 & Haikou, Hainan & 47 & A105 & Changjiang, Hainan \\
\hline 16 & A41 & Menghai, Yunnan & 48 & A106 & Hepu, Guangxi \\
\hline 17 & A42 & Ledong, Hainan & 49 & A107 & Hepu, Guangxi \\
\hline 18 & A45 & Yingde, Guangdong & 50 & A108 & Hepu, Guangxi \\
\hline 19 & A47 & Hekou, Yunnan & 51 & A111 & Yulin, Guangxi \\
\hline 20 & A49 & Ceheng, Guizhou & 52 & A113 & Leizhou, Guangzhou \\
\hline 21 & A51 & Zhangpu, Fujian & 53 & A114 & Haikou, Hainan \\
\hline 22 & A52 & Wuzhou, Guangxi & 54 & A116 & Maoming, Guangdong \\
\hline 23 & A54 & Huizhou, Guangdong & 55 & A118 & Dianbai, Guangdong \\
\hline 24 & A57 & Zhangzhou,Fujian & 56 & A120 & Yulin, Guangxi \\
\hline 25 & A58 & Guangzhou, Guangdong & 57 & A121 & Leizhou, Guangzhou \\
\hline 26 & A59 & Nanjing, Fujian & 58 & A122 & Xuwen, Guangdong \\
\hline 27 & A63 & Mangshi, Yunnan & 59 & A123 & Lianjiang, Guangdong \\
\hline 28 & A67 & Mangshi, Yunnan & 60 & A126 & Suixi, Guangdong \\
\hline 29 & A70 & Ruili, Yunnan & 61 & A139 & Qiongzhong, Hainan \\
\hline 30 & A72 & Ruili, Yunnan & 62 & A140 & Shangsi, Guangxi \\
\hline 31 & A81 & Changtai, Fujian & 63 & A141 & Wuzhishan, Hainan \\
\hline 32 & A 82 & Fusui, Guangxi & & & \\
\hline
\end{tabular}

fresh, healthy leaf samples following the CTAB (Hexadecyl trimethyl ammonium Bromide) method described by Doyle and Doyle (1987). DNA quality was checked in $1.5 \%$ agarose gels, and DNA concentrations were determined by reference to a sample of known concentration. Genomic DNA was diluted to a final concentration of $50 \mathrm{ng} \cdot \mu \mathrm{L}^{-1}$ and stored at $-20{ }^{\circ} \mathrm{C}$ for further analysis.

SSR primers. We used Roche 454 sequencing combined with the magnetic bead enrichment method of FIASCO to isolate SSR markers from the carpetgrass genome. A total of 1,942 microsatellite loci were identified in 53,193 raw sequencing reads. To test the primer amplification efficiency, we randomly selected 100 microsatellite sequences to design primer pairs and deposited these sequences in GenBank (KM110853-KM110930) (Table 2). Fourteen of the 100 primer pairs were selected to amplify polymorphisms in the 63 carpetgrass accessions from China (Table 1).

Primer screening and DNA amplification. Fourteen primer pairs with clear gel bands, reproducible fragments, and strong signal were used for further analyses. PCR amplification followed previously established protocols (Wang et al., 2007). A 20- $\mu \mathrm{L}$ volume of PCR mixture consisted of $3 \mu \mathrm{L}$ of $10 \mathrm{x}$ buffer $(100 \mathrm{~mm}$ Tris- $\mathrm{HCl} \mathrm{pH} \mathrm{8.3,500} \mathrm{mM} \mathrm{KCl,} 15 \mathrm{~mm}$ $\mathrm{MgCl}_{2}$ ), $1.5 \mu \mathrm{L}$ dNTPs, $1.0 \mu \mathrm{L}$ each forward and reverse primers, $0.2 \mu \mathrm{L}$ Taq DNA poly-

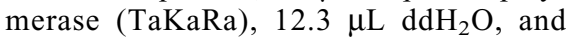
$1.0 \mu \mathrm{L}$ DNA template $\left(50 \mathrm{ng} \cdot \mu \mathrm{L}^{-1}\right)$. The PCR amplifications were carried out in a TECHNE TC-412 machine (Bibby Scientific, Staffordshire, UK) with the following protocol: $94{ }^{\circ} \mathrm{C}$ for 5 min for initial denaturation; 37 cycles of

Table 2. Amplification information of simple sequence repeat primers in carpetgrass accessions.

\begin{tabular}{|c|c|c|c|c|c|c|c|}
\hline Primer & Primer sequence $\left(5^{\prime}-3^{\prime}\right)$ & Repeat motif & $\begin{array}{c}\mathrm{Ta} \\
\left({ }^{\circ} \mathrm{C}\right)\end{array}$ & $\begin{array}{c}\text { Allele } \\
\text { Size (bp) }\end{array}$ & $\begin{array}{l}\text { No. of } \\
\text { alleles }\end{array}$ & $\begin{array}{c}\text { No. of } \\
\text { polymorphic } \\
\text { bands }\end{array}$ & $\begin{array}{c}\text { GenBank } \\
\text { Accession no. }\end{array}$ \\
\hline & F: TTATAGGGCCTCACAAAGCG & & 60 & $184-205$ & 2 & 1 & KM110853 \\
\hline ID19 & R: CTCCTGCTCCTGCTGCTACT & (TAG)5(GAG)6A(AGG)5 & & & & & \\
\hline \multirow[t]{2}{*}{ ID21 } & R: TAATGCACGCCCATAGAACA & (AC) $15(\mathrm{AT}) 7$ & & & & & \\
\hline & F: AGCATCGTCGAAAAACCTGT & & 60 & $231-294$ & 3 & 3 & KM110859 \\
\hline ID25 & R: TTGCATGAAAGTAAAGCAATGAA & (ATG) 17 & & & & & \\
\hline ID34 & F: GGTCCATCATCCTCCAAGAA & & 60 & $344-353$ & 3 & 3 & KM110875 \\
\hline \multirow[t]{2}{*}{ ID41 } & R: ACTTGGAGGTCACTTGCGAT & $(\mathrm{AAG}) 5 \ldots$ (TGA) 6 & & & & & \\
\hline & F: TGAAGTCAATTAGGATTTTTATGGG & & 60 & $304-400$ & 3 & 3 & KM110901 \\
\hline \multirow[t]{2}{*}{ ID67 } & R: TGCGAGATGAGTTCGAGTATC & (TATG)29...(TATG)5 & & & & & \\
\hline & F: TTCCCCACTAAAAATGACGG & & 56 & $173-189$ & 3 & 3 & KM110907 \\
\hline \multirow[t]{2}{*}{ ID73 } & R: CAATCTTATCCGCCATGAAA & $(\mathrm{GT}) 6(\mathrm{AT}) 8(\mathrm{GT}) 13$ & & & & & \\
\hline & F: GCTTTCTCGAGAGTCATCCG & & 56 & $137-188$ & 4 & 4 & KM110913 \\
\hline ID85 & F: AGGGGGCAGCTCATTTTTAT & & 56 & $290-380$ & 6 & 6 & KM110921 \\
\hline \multirow[t]{2}{*}{ ID87 } & R: ATTCAGGACTCGGTTGATGC & (AT) $6(\mathrm{AC}) 27$ & & & & & \\
\hline & F: GCTCCACATCTTTCTGCGAT & & 60 & $253-269$ & 4 & 4 & KM110925 \\
\hline \multirow[t]{2}{*}{ ID91 } & R: ACCATATGTACAAGGTGCTAGTTAGG & (TATG) 13 & & & & & \\
\hline & F: GGCCATATAAGGTGACGCAT & & 60 & 329-389 & 2 & 2 & KM110928 \\
\hline \multirow[t]{2}{*}{ ID94 } & R: TTTTCATGGTTGCCAAATCA & (AAT)11(AAC)15 & & & & & \\
\hline & F: GAGGGGGCTAGGCATTTTAG & & 56 & $192-220$ & 3 & 3 & KM110930 \\
\hline ID96 & R: TGAAATGCAAGCACACACAA & (TG) $8 \ldots$ (TG) 9 & & & & & \\
\hline Total & & & & & 49 & 48 & \\
\hline Average & & & & & 3.5 & 3.4 & \\
\hline
\end{tabular}


denaturing at $94{ }^{\circ} \mathrm{C}$ for $45 \mathrm{~s}$, annealing at $48.0-60.0^{\circ} \mathrm{C}$ for $45 \mathrm{~s}$, and elongation at $72{ }^{\circ} \mathrm{C}$ for $78 \mathrm{~s} ; 72{ }^{\circ} \mathrm{C}$ for $7 \mathrm{~min}$ for a final extension; and holding at $4{ }^{\circ} \mathrm{C}$. The amplified products $(3 \mu \mathrm{L})$ were separated on an $8.0 \%$ nondenaturing polyacrylamide gel (in $1 \mathrm{x}$ TBE buffer) at $200 \mathrm{~V}$ for $2.5 \mathrm{~h}$ at room temperature using a Hoefer vertical-gel apparatus (JY-SCZ7). After electrophoresis, the gels were silverstained for detection (Wang et al., 2007). Allele sizes were estimated using a 100 base pair (bp) DNA ladder (Takara, Dalian, Liaoning, China) as reference.

Data analysis. Bands of the amplified fragments were recorded as present (1) or absent (0). According to method of Nei and Li (1979), genetic similarity coefficients (GSCs) of the 63 accessions were calculated by using Numerical Taxonomy and Multivariate Analysis System (NTSYS-pc) (v. 2.10s) software (Rohlf, 1993). Genetic polymorphism (P-5\%), Nei's gene diversity $(\mathrm{He})$, and Shannon's information index (I) were used to calculate Nei's standard genetic distance coefficients (Nei and $\mathrm{Li}, 1979$ ) and to construct a UPGMA dendrogram within the sequential agglomerative hierarchical nested cluster analysis (SAHN) module of NTSYS (Sneath and Sokal, 1973).

\section{Results}

SSR analysis. Fourteen SSR primer pairs (Table 2) were used to examine the genetic similarities among the 63 carpetgrass accessions. Of a total of 49 amplified fragments, 48 (97.96\%) were polymorphic, with an average of 3.5 amplified bands per primer pair (Table 2; Fig. 1). The polymorphism was either $100 \%$ (ID21, ID25, ID34, ID41, ID67, ID73, ID79, ID84, ID85, ID87, ID91, ID94, and ID96) or $50 \%$ (ID19). PCR product sizes ranged from 100 to $400 \mathrm{bp}$.

Statistical analysis. The coefficients of genetic similarity among the 63 carpetgrass accessions ranged from 0.24 to 0.98 . The closest genetic relationship was between samples from Hepu, Guangxi Province (A106 and A108), with a GSC of 0.98 . The lowest GSC of 0.24 was between accessions from Xiamen, Fujian Province (A83) and Wuzhishan, Hainan Province (A141). Overall, the accessions were closely related, and the largest GSC values were from the same or similar geographic locations.

Cluster analysis. The UPGMA cluster analysis of SSR results of the 63 carpetgrass accessions resulted in a dendrogram of genetic relationships that agreed with the pedigrees and geographic origins of the plants. There were three main clusters (I, II, and III) (Fig. 2). Cluster I included 38 accessions from Hainan (16 accessions), Fujian (6), Guangdong (3), Guangxi (5), Yunnan (7), and Guizhou (1) provinces. This group was characterized by excellent turf characteristics, including relatively slow vertical growth (was calculated as the height of the grass layer divided by $28 \mathrm{~d}$ ); a high coefficient of expansion [was calculated as the total length of stolons in the plot divided by

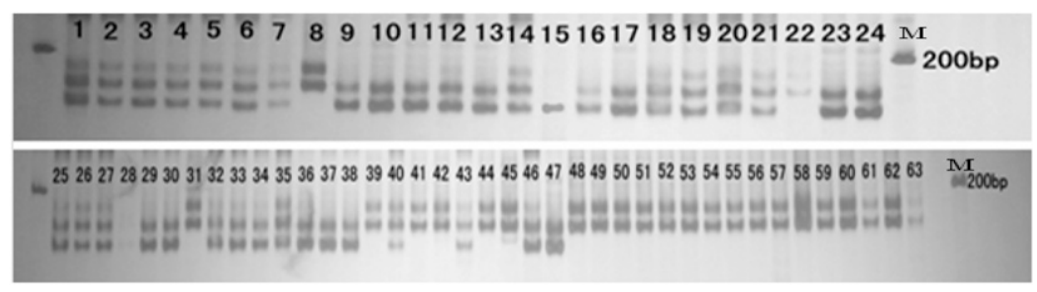

Fig. 1. Simple sequence repeat amplified with primer ID73 in 63 DNA of carpetgrass, Marker is 100-base pair DNA ladder, material number was showed in Table 1.

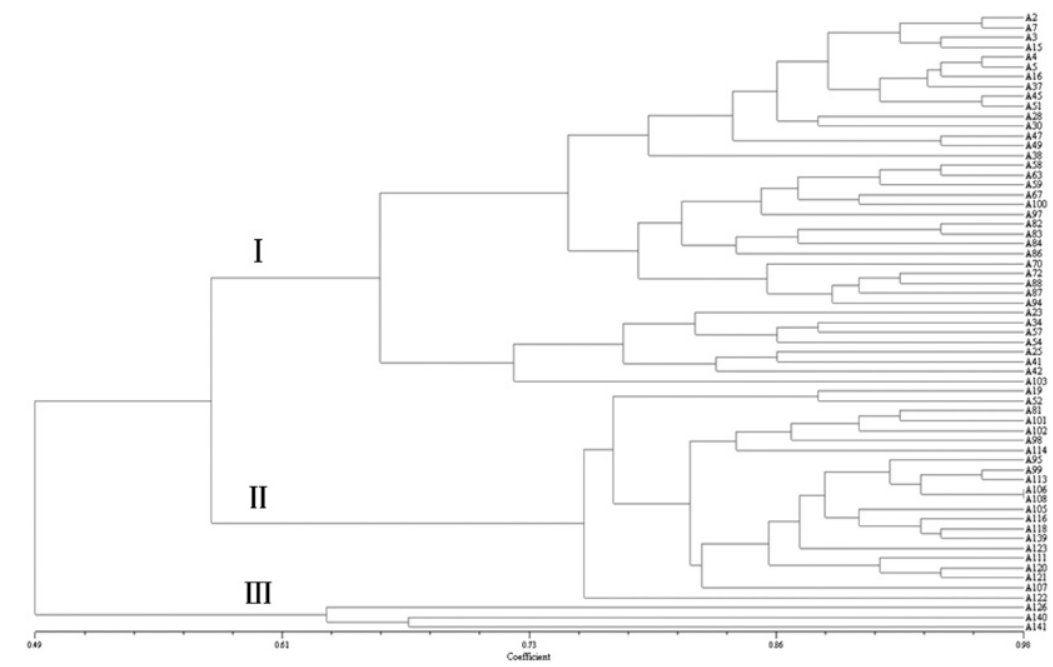

Fig. 2. UPGMA clustering for 63 carpetgrass accessions based on simple sequence repeat marker.

the perimeter of plot $(2.0 \mathrm{~m})]$; horizontal growth rate of a single branch (was calculated as the total length of stolons in the plot divided by $28 \mathrm{~d}$ ); and very high numbers of both primary [was calculated as the number of primary branches in the plot divided by the plot perimeter $(2.0 \mathrm{~m})$ ] and secondary stolon branches per unit perimeter [was calculated as the number of secondary branches in the plot divided by the plot perimeter $(2.0 \mathrm{~m})$ ]. Two cluster I accessions, from Hainan (A30) and Guangdong (A58) provinces, had better vegetative propagation traits than the Huanan cultivar (control varieties) used in this study. Cluster II contained 22 accessions from Guangdong (8), Guangxi (7), Fujian (1), Hainan (5), and Yunnan (1) provinces. The asexual reproduction characteristics of this group were generally between those of Clusters I and III, these accessions may be useful in some breeding situations. Cluster III comprised three accessions, one each from Hainan, Guangdong, and Guangxi provinces, with opposite characteristics to those in Cluster I. Not all accessions from the same region clustered in the same group.

\section{Discussion}

SSRs have become one of the most widely used types of molecular markers in recent years. They have several advantages over many other DNA markers, such as high polymorphism rates, abundance, genetic codominance, and the availability of specific PCR-based assays (Pejic et al., 1998). For instance, in this study, some accessions from the same region were similar in morphology but could be distinguished by the SSR markers. Thus, SSRs are very useful molecular markers for studying carpetgrasses in large-scale breeding programs (Tang et al., 2007).

At present, genetic diversity analyses using microsatellite markers have been reported in turf and forage grasses, including bermudagrass [Cynodon dactylon (L.) Pers.; Wang et al., 2013], zoysiagrass (Zoysia japonica Steud.; Li et al., 2009), and centipedegrass [Eremochloa ophiuroides (Munro) Hack; Zheng et al., 2013]. However, there have been no similar publications on carpetgrass. This study is the first assessment of molecular genetic diversity in carpetgrass accessions.

We analyzed the genetic relationships of 63 carpetgrass accessions from China using SSR molecular markers. The GSCs ranged from 0.24 to 0.98 . This result suggested that the analyzed germplasms possessed a great amount of variation and represented the diversity of the source germplasms (Chen and $\mathrm{Du}, 2006)$. Wu et al. (2006) showed that the GSC ranged from 0.65 to 0.99 (average 0.82) among 119 bermudagrass accessions based AFLP markers. Wang et al. (2010) observed that the GSC ranged from 0.807 to 0.98 (average 0.89) among 59 common carpetgrass [A. fissifolius (Raddi) Kuhlm.] accessions. These studies and our own data indicated that the carpetgrass accessions possessed great genetic diversity. Carpetgrass has 
many ploidy levels $(2 \mathrm{n}=40,50$, and 60$)$ (Delay, 1950), which may increase genetic differentiation (Wang et al., 2010). Based on our results, we will next analyze the ploidy levels of these carpetgrass accessions, because ploidy level might be affected by the environment or by the evolutionary histories of the genotypes (Johnsonet al., 1998). Wu et al. (2006) and Wang et al. (2010) reported similar results for the relationship between genetic diversity and ploidy level of bermudagrass and common carpetgrass accessions, respectively.

Of a total of 49 amplified fragments, 48 $(97.96 \%)$ were polymorphic, with an average of 3.5 amplified bands for each primer pair. The 63 carpetgrass accessions clustered into three groups by UPGMA (Fig. 2), which appeared to be associated with geographic origin and genetic factors, a phenomenon seen in other plant germplasms (Blair et al., 1999; Bornet et al., 2002; Godwin, et al., 1997; Li and Ge, 2001; Tani et al., 1998; Wang et al., 2010; Wang et al., 2013). Similar results were obtained in Lolium perenne ( $\mathrm{Li}$ et al., 2013) and Agropyron (Zeng et al., 2013). The reasons for these results might be as follows: first, accessions from different geographical areas clustered into the same group because of environmental pressures leading to long-term adaptation, so some traits were shared among different carpetgrass germplasms (Zeng et al., 2013). Second, carpetgrass has strong vegetative reproduction ability, especially famous to its leanness resistance and extensive management (Xi et al., 2004b). Third, carpetgrass is a perennial, outcrossing grass, which may lead to rich genetic variation in accessions from different regions. Finally, the multiple ploidy levels of carpetgrass may also promote this phenomenon (Delay, 1950).

In conclusion, this study was the first to use microsatellite markers in Axonopus and revealed great genetic diversity in carpetgrass germplasms. This project will provide important methods and technology for future research. The microsatellite markers developed here for Axonopus could be helpful for different objectives related to genetic diversity, including assisted breeding and assessing the diversity of wild germplasm resources. Therefore, the use of SSR markers to test differences among germplasms was more effective in detecting genomic variation and may provide valuable references for cross breeding.

\section{Literature Cited}

Blair, M.W., O. Panaud, and S.R. Mccouch. 1999. Inter-simple sequence repeats (ISSR) amplification for analysis of microsatellite motif frequency and fingerprinting in rice (Oryza sativa L.). Theor. Appl. Genet. 98:780-792.

Bornet, B., F. Goraguer, G. Joly, and M. Branchard. 2002. Genetic diversity in European and Argentinean cultivated potatoes (Solanum tuberosum subsp. Tuberosum) detected by inter-simple sequence repeats (ISSRs). Genome 45:481-484.

Chen, G. and X.M. Du. 2006. Genetic diversity of source germplasm of upland cotton in China as determined by SSR marker analysis. Acta Genetica Sin. 33:733-745.

Delay, C. 1950. Nombres chromosomiques chez les Phanérogames. Rev. Cytol. et Biol. Veg. 12:1-368.

Doyle, J.J. and J.L. Doyle. 1987. A rapid DNA isolation procedure for small quantities of fresh leaf tissue. Phytochem Bull. 19:11-15.

Godwin, I.D., E.A.B. Aitken, and I.W. Smith. 1997. Application of inter-simple sequence repeat (ISSR) markers to plant genetics. Electrophoresis 18:1524-1528.

Hanna, W.W. and G.W. Burton. 1978. Cytology, reproductive behavior, and fertility characteristics of centipedegrass. Crop Sci. 18:835837.

Harris-Shultz, K., P. Raymer, B.E. Scheffler, and R.S. Arias. 2013. Development and characterization of seashore paspalum SSR markers. Crop Sci. 53:2679-2685.

Heath, M.E., R.F. Barnes, and D.S. Metcalfe. 1985. Forages: The science of grassland agriculture. Iowa State University Press, Ames, IA.

Johnson, P.G., T.P. Riordan, and K. Arumuganathan. 1998. Ploidy level determinations in buffalograss clones and populations. Crop Sci. 38:478-482.

Li, A. and S. Ge. 2001. Genetic variation and clonal diversity of Psammochloa villosa (Poaceae) detected by ISSR markers. Ann. Bot. 87:585590.

Li, J.Q., L.H. Wang, Q.W. Zhan, K. Zhu, J.L. Liu, and W.X. Li. 2013. Genetic diversity of 20 ryegrass accessions by SRAP markers. Acta Pratacult. Sin. 22:158-164.

Li, M.L., N. Yuyama, M. Hirata, J.G. Han, Y.W Wang, and H.W. Cai. 2009. Construction of a high-density SSR marker-based linkage map of zoysiagrass (Zoysia japonica Steud.). Euphytica 170:327-338.

Liao, L., X.H. Huang, C.J. Bai, and Z.Y. Wang. 2011. Study on responses of Axonopus compressus (Sw.) Beauv. to aluminum stress and critical aluminum concentration. Chinese J. Trop. Crops 32:1235-1239.

Liu, G.D. 2010. Poaceae of Hainan. Science Press, Beijing, China.

Madesis, P., E.M. Abraham, A. Kalivas, I. Ganopoulos, and A. Tsaftaris. 2014. Genetic diversity and structure of natural Dactylis glomerata L. populations revealed by morphological and microsatellitebased (SSR/ISSR) markers. Genet. Mol. Res. 13:4226-4240.

Nei, M. and W.H. Li. 1979. Mathematical model for studying genetic variation in terms of restriction endonucleases. Proc. Natl. Acad. Sci. USA 76:5269-5273.

Pejic, I., M.P. Ajmone, M. Morgante, V. Kozumplick, P. Castaglioni, G. Taramino, and M. Motto. 1998. Comparative analysis of genetic similarity among maize inbred lines detected by RFLPs, RAPDs, SSRs and AFLPs. Theor. Appl. Genet. 97:12481255.

Rohlf, F.J. 1993. NTSYS-pc version1.80 [M/CD]. Distribution by Exeter Software, Setauket, New York.

Samarakoon, S.P., J.R. Wilson, and H.M. Shelton. 1990. Growth, morphology and nutritive quality of shaded Stenotaphrum secundatum, Axonopus compressus, and Pennisetum clandestinum. J. Agr. Sci. 114:161-169.

Schlotterer, C. 2004. The evolution of molecular markers-just a matter of fashion? Nat. Rev. Genet. 5:63-69.

Smith, M.A. and P.C. Whiteman. 1983. Evaluation of tropical grasses in increasing shade under coconut canopies. Exp. Agr. 19:153161 .
Sneath, P.H.A. and R.R. Sokal. 1973. Numerical Taxonomy. Freeman, San Francisco, CA.

Song, Y., L. Fan, H. Chen, M.Y. Zhang, Q.Q. Ma, S.L. Zhang, and J. Wu. 2014. Identifying genetic diversity and a preliminary core collection of Pyrus pyrifolia cultivars by a genome-wide set of SSR markers. Sci. Hort. 167:5-16.

Tang, R.T., G.Q. Gao, L.Q. He, Z.Q. Han, S. Shan, R.C. Zhong, C.Q. Zhou, J. Jiang, Y.R. Li, and W.J. Zhuang. 2007. Genetic diversity in cultivated groundnut based on SSR markers. J. Genet. Genomics 34:449-459.

Tani, N., N. Tomaru, Y. Tsumura, M. Araki, and K. Ohba. 1998. Genetic structure within a Japanese stone pine (Pinus pumila Regel) population on Mt.Aino-Dake in Central Honshu, Japan. J. Plant Res. 111:7-15.

Uddin, M.K., A.S. Juraimi, and M.R. Ismail. 2009. Growth response of eight tropical turfgrass species to salinity. Afr. J. Biotechnol. 8:57995806.

Wang, Z., K.E. Kenworthy, and Y.Q. Wu. 2010. Genetic diversity of common carpetgrass revealed by amplified fragment length polymorphism markers. Crop Sci. 50:1366-1374.

Wang, Z.Y., H.L. Guo, and J.X. Liu. 2007. Optimization of SSR-PCR system on Cynodon spp. by orthongonal design. Mol. Plant Breed. 5:201206.

Wang, Z.Y., L. Liao, X.J. Yuan, H.L. Guo, A.G. Gao, and J.X. Liu. 2013. Genetic diversity analysis of Cynodon dactylon (bermudagrass) accessions and cultivars from different countries based on ISSR and SSR markers. Biochem. Syst. Ecol. 46:108-115.

Wang, Z.Y., X.J. Yuan, and J.X. Liu. 2009. Molecular identification and genetic analysis for 24 turftype Cynodon cultivars by Sequence-Related Amplified Polymorphism markers. Sci. Hort. 122:461-467.

Weising, K., H. Nybom, K. Wolff, and G. Kahl. 2005. DNA Fingerprinting in Plants: Principles, Methods, and Applications, 2nd ed. CRC PressTaylor \& Francis Group, Boca Raton, FL.

Weng, J.H., M.J. Fan, C.Y. Lin, Y.H. Liu, and S.Y. Huang. 2007. Genetic Variation of Zoysia as revealed by random amplified polymorphic DNA (RAPD) and Isozyme pattern. Plant Prod. Sci. 10:80-85.

Wu, Y.Q., C.M. Taliaferro, G.H. Bai, D.L. Martin, J.A. Anderson, M.P. Anderson, and R.M. Edwards. 2006. Genetic analysis of Chinese Cynodon accessions by flow cytometry and AFLP markers. Crop Sci. 46:917926.

Xi, J.B., P. Chen, and H.X. Zhang. 2006. Studies on the drought tolerance of wild germplasm resources of Axonopus compressus in China. Acta Pratacult. Sin. 15:93-99.

Xi, J.B., P. Chen, Y.Z. Zheng, and Z.Y. Yang. 2004a. An investigation of Axonopus compressus germplasm resources in China. Acta Pratacult. Sin. 13:52-57.

Xi, J.B., Y.Z. Zheng, and Z.Y. Yang. 2004b. Establishment and optimization of ISSR reaction system for carpetgrass. Acta Scientiarum Naturalium Un. 43:80-84.

Zeng, L., Q.H. Yuan, F. Wang, and Y. Wang. 2013. Genetic diversity analysis of Agropyron germplasm resources by ISSR. Acta Pratacult. Sin. 22:260-267.

Zheng, Y.Q., H.L. Guo, G.Z. Zang, and J.X. Liu. 2013. Genetic linkage maps of centipedegrass [Eremochloa ophiuroides (Munro) Hack] based on sequence-related amplified polymorphism and expressed sequence tagsimple sequence repeat markers. Sci. Hort. 156:86-92. 